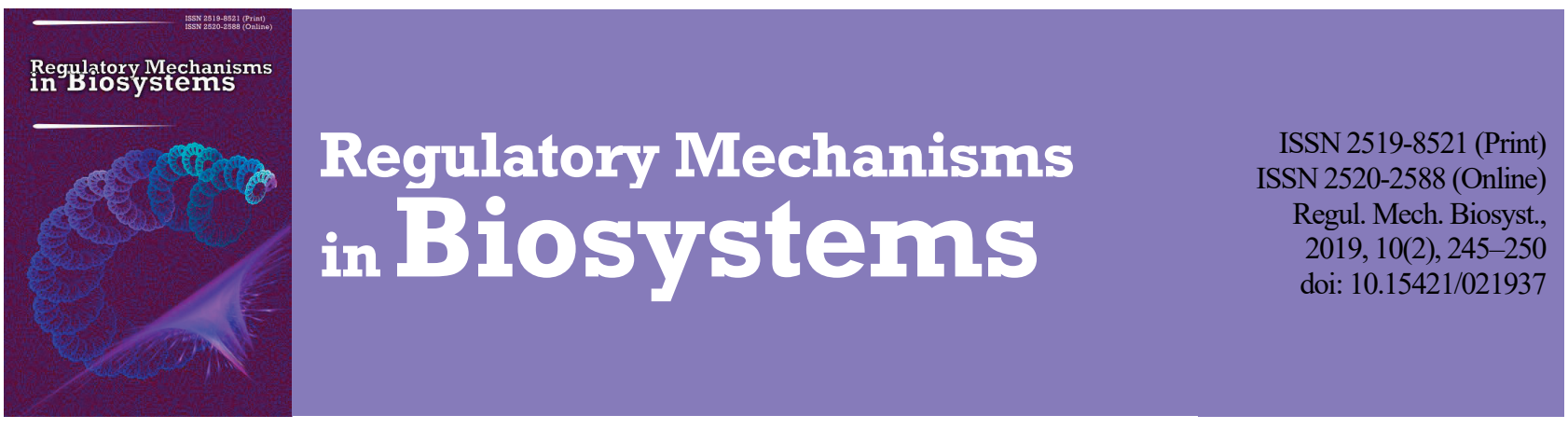

\title{
Evaluation of anti-microbial activity of filtrates of Lactobacillus rhamnosus and Saccharomyces boulardii against antibiotic-resistant gram-negative bacteria
}

\author{
O. Y. Isayenko*, O. V. Knysh*, O. V. Kotsar**, T. N. Ryzhkova***, G. I. Dyukareva**** \\ *I. I. Mechnikov Institute of Microbiology and Immunology of National Academy of Medical Sciences of Ukraine, Kharkiv, Ukraine \\ **Kharkiv National Medical University, Kharkiv, Ukraine \\ ***Kharkiv State Zooveterinary Academy, Kharkiv, Ukraine \\ ****Kharkiv State University of Food Technology and Trade, Kharkiv, Ukraine
}

Article info

Received 02.05.2019

Received in revised form 28.05 .2019

Accepted 29.05.2019

I. I. Mechnikov Institute of Microbiology and Immunology of National Academy of Medical Sciences of Ukraine, Pushkinska st., 14/16, Kharkiv, 61057, Ukraine. Tel.: +38-099-43-41-830. E-mail:el_isaenko@ukr.net

Kharkiv National Medical University, Nauky av., 4, Kharkiv, 61022, Ukraine.

Kharkiv State Zooveterinary Academy, Akademichna st., 1 , Mala Danylivka, Kharkiv region, 62341, Ukraine

Tel.: +38-096-384-60-58.

E-mail:rujkova.ua@gmail.com

Kharkiv State University of Food Technology and Trade Klochkivska st., 333 ,

Kharkiv, 61051, Ukraine.

\section{Introduction}

Among the great variety of infectious diseases, diseases of the respiratory system remain highly relevant (Dorofeev et al., 2017; Jakovlev, 2017; Ponomarev, 2017). According to the data of the WHO, in countries with a low level of income, respiratory infections of the lower respiratory tract take first place out of the ten leading causes of death in the world (WHO, 2017). Especially dangerous are acute respiratory diseases caused by multi drug-resistant pathogens (Wald, 2011). Difficulty in treating such infectious diseases occurs not only due to non-effective antibacterial therapy, but also the ability of polyresistant pathogens to transmit resistance to other microorganism (Arcilla, 2017, Tsutsui et al., 2018). This fact was found in Escherichia coli, Pseudomonas aeruginosa, Burkholderia cenocepacia (El-Halfawy et al., 2013).

Reasons for development of the majority of chronic respiratory diseases are antibiotic-resistant microorganisms, from which, according to the WHO, several hundred million people suffer (WHO, 2018). Thanks to scientific studies in the sphere of studying multi-resistance of bacteria to anti-microbial preparations, and on the basis of data of the European Centre for Disease Prevention and Control, it was proved that because of antibiotic-resistant bacteria, around 25 thousand people in the European Union die each year (Ursova, 2013). Scientists presume that in next 20 years practical medicine will lose its last efficient anti-bacterial preparations (Kraker et al., 2016).

Another problem is increase in the number of gram-negative bacteria in biotopes which are untypical for these microorganisms (Beyer et al., 2000). The development of disbalance of bacterial microflora with changes in quantitative and qualitative composition, which affects different regions of the macroorganism, including the nasopharyngeal and oral cavities, has been observed in most people of our planet (Ursova, 2013, Östholm et al., 2018). Furthermore, it is characterized by frequent release of antibiotic-resistant gram-negative microorganisms out of these cavities (Santajit \& Indrawattana 2016).

According to the data of the WHO, nine out of twelve conditionally pathogenic pathogens which are in leading positions among polyresistant microorganisms are gram-negative bacteria (WHO, 2017). These are the carbapenem-resistant Enterobacteriaceae, Acinetobacter baumannii and Pseudomonas aeruginosa. Among the microorganisms which cause hospital-acquired infections, a leading position is taken by gramnegative bacteria. Out of six pathogens of ENSKAPE, two are gram- 
positive and four are gram-negative: Enterococcus faecium, Staphylococcus aureus, Klebsiella pneumoniae, Escherichia coli, Acinetobacter baumannii, Pseudomonas aeruginosa and different species of Enterobacter (Santajit \& Indrawattana 2016; Lupo et al., 2018; Ramsamy et al., 2018). Stopping increase in the specific weight of polyresistant gramnegative infections has been partly achieved by undertaking epidemiologic monitoring in hospitals, introduction of new medical preparations, and improvement of hygiene. The difficulty of treatment against gramnegative pathogens consists in the special structure of their cellular membrane which functions as an additional protective barrier and obstructs the introduction of anti-bacterial preparations inside the cell (Malanovic et al., 2016; Ebbensgaard et al., 2018). Their cellular membrane contains two lipid membranes in contrast to the gram-positive bacteria with only one (Richter \& Hergenrother, 2019). The external layer of the external membrane of gram-negative bacteria consists of lipopolysaccharides (LPS). Lipid A in its content and long oligosaccharide allows the LPS molecules to form dense aggregations and obstructs the passive diffusion of even small molecules of medical preparations. Penetration of small molecules through pores (canals) formed by transmembrane ion channel proteins (porins) remains possible. However, almost all introduced medical substances are removed from the cell by efflux pump (Santajit \& Indrawattana 2016; Lupo et al., 2018; Ramsamy et al., 2018). In gram-negative microorganisms, the efflux pumps have three components (transporter, canal-forming protein and the protein which binds them) by contrast to one-component ones in gram-positive bacteria. Removal of medical substances occurs due to canal-forming protein which locates in the external membrane (Nikaido, 2011). Today, when antibiotic-resistance of microorganisms progresses, and the arsenal of efficient anti-microbial preparations is becoming depleted at a catastrophically pace, it is becoming a serious threat for mankind (Mitsakakis et al., 2018).

Among the potential varieties of alternative anti-bacterial preparations with notable anti-microbial properties against polyresistant pathogens, the advantage belongs to probiotic live bacteria and their exometabolites (Mirnejad, 2013). Optimistic prognoses which were made earlier, and have been confirmed over recent years emerged due to a new approach to using products of vital activity of probiotic microorganisms for treatment and prevention of diseases of different genesis. Over several decades, more than fifty peptide bacteriocins with detailed characteristics of their biological composition and mechanisms of effect have been analyzed and presented. It was also determined that in low concentrations anti-bacterial substances produced by lactic bacteria efficiently affect gram-positive bacteria and microorganisms related to the primary producer strain (Nes et al., 2000). They have no effect on gram-negative pathogens. The results presented in contemporary scientific publications have confuted the earlier demonstrated data on the limited range of impact of anti-bacterial components obtained from probiotic microorganisms. It was determined that biologically active substances (anti-microbial peptides) can affect the cellular membrane, cellular wall, inhibit synthesis of protein/activity of enzyme or take effect inside the cell. Therefore, after the peptide reaches the cellular wall, cellular membrane or a target inside the cell, the difference in mechanism of effect on gramnegative and gram-positive microorganisms is not significant (Bechinger \& Gorr, 2016). Anti-microbial effect of L. casei subsp. rhamnosus Lcr35 supernatant has been proven against representatives of Escherichia coli, Klebsiella pneumoniae, Shigella flexneri, Salmonella typhimurium, Pseudomonas aeruginosa, Enterococus faecalis and Clostridium difficile (Forestier et al., 2001). A high extent of anti-fungicidal activity was demonstrated by biological substances from Lactobacillus plantarum, against Aspergillus niger, Rhizopus stolonifer, Mucor racemosus and Penicillium chrysogenum (Gupta et al., 2014). According to some scientists, antibacterial properties are conditioned by lactic acid and other organic acids. Alokomi et al. (2000) have proved the property of lactic acid produced by Lactobacillus to increase the sensitivity of pathogens to anti-microbial substances. Other authors are of a similar opinion, stating that anti-microbial effect against gram-positive and gramnegative microorganisms by biologically active substances from lactobacteria is conditioned not only by lactic acid and hydrogen peroxide (Nomoto, 2005; Portella et al., 2009). At the same time, the synergic effect of lactic acid and protein substances is also considered possible. There has also been observed a strengthening of the effect at synergic use of two anti-bacterial substances, in comparison to their multi-component usage. The substances are nisin A produced by Lactobacillus lactis in 1928 and poly-L-lisin from Streptomyces albulus 346, which at combined application inhibit the antibiotic-resistant streptococcus $S$. mutans. Combined use of these anti-microbial substances contributed to complete elimination of the resistant Streptococcus along with less inhibitory effect on the general aerobic microflora of the oral cavity (Badaoui et al., 2009).

Products of vital activity of probiotic microorganisms provide additional interest to scientists due to their polyfunctional abilities: they prevent growth, breeding, affect the process of biofilm formation and damage pre-formed biofilms of gram-positive and gram-negative bacteria and fungi (Wang et al., 2017). According to numerous scientific studies, the range of activity of bacteriocins, exometabolites, probiotic microorganisms has enlarged, the possibilities of using substances with high anti-bacterial properties have been extended, which allows them to be successfully used for treatment of genitourinary, nasopharyngeal, wound infections and for preventing allergies.

After we had analyzed domestic and foreign studies as well as the obtained information, as test-objects we selected pathogens with multi resistance to medications, isolated from patients with inflammatory and pus-inflammatory diseases of the respiratory tract. The objective of the study was creating anti-microbial substances against etiogically significant antibiotic-resistant gram-negative conditionally pathogenic bacteria on the basis of metabolites from lactobacteria and saccharomycetes obtained from cultivation of the primary producers in disintegrates of probiotic strains of microorganisms.

\section{Materials and methods}

For obtaining biologically active substances we used the derivative cultures of bacteria and fungi:

1) Lactobacillus rhamnosus $\left(\mathrm{LGG}^{\circledR}\right)$ ATCC 53103 (L. rhamnosus

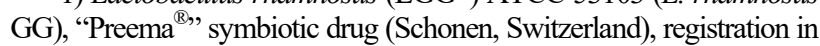
Ukraine No 05.03.02-03/28238.

2) Saccharomyces boulardii CNCM I-745, Bulardi ${ }^{\mathbb{R}}$ preparation (Schonen, Switzerland), registration in Ukraine No 05.03.02-03/58212. Studied material:

1) filtrates of ultrasound disintegrates of lactobacteria (L) and saccharomycetes (S) (contain structural components of bacterial cells);

2) filtrates of cultures of lactobacteria (ML), saccharomycetes (MS, LS), and combined cultures of lactobacteria and saccharomycetes (MLS), obtained by cultivating the primary producers in ultrasound disintegrates (contain structural-metabolite complexes of bacterial cells and fungi).

For obtaining disintegrates and metabolites, which were biologically active substances from $L$. rhamnosus $\mathrm{GG}$ and $S$. boulardii, we prepared weighed amounts of microorganisms using McFarland scales (10.0 units of McF) on a Densi-La-Meter device (PLIVA-Lachema Diagnostika, (Czech Republic)).

Obtaining of disintegrates (structural components) of industrial cultures of bacteria and fungi: using a G3-109 low-frequency generator loaded on circular piezoelectric convertors, we affected the suspensions of $L$. rhamnosus GG or $S$. boulardii probiotic strains for obtaining disintegrates or structural components of L. rhamnosus GG (sample L) or S. boulardii (sample $\mathrm{S}$ ).

Obtaining of metabolites (structural-metabolite substances) from bacteria and fungi in disintegrates of probiotic cultures:

1) metabolites from Lactobacillus were obtained by cultivation of suspensions of L. rhamnosus GG with optical density of 10.0 units according to McF scale in their disintegrates (sample ML) (Isajenko et al., 2017);

2) metabolites from Saccharomyces were isolated in a similar way, by growing suspensions of $S$. boulardii in their disintegrates of fungi (sample MS);

3) metabolites from Saccharomyces, differed from the previous by cultivating suspensions of fungi in disintegrate of bacteria ( $L$. ${ }^{\circ}$ rhamnosus) (sample LS);

4) combination of metabolites from Lactobacillus and Saccharomyces were obtained by combined growing of microbial cells of $L$. 
rhamnosus GG and S. boulardii in disintegrate of lactobacteria (Sample MLS) (Isajenko et al., 2018).

The impact of disintegrates of $L$. rhamnosus GG and S. boulardii and their metabolites on growth and reproduction of conditionally pathogenic representatives was studied on test-cultures of gram-negative bacteria with multiple anti-microbial resistance (to levofloxacin, ceftriaxone, ciprofloxacin, doxycycline, ampicillin): Pseudomonas aeruginosa PR, Klebsiella pneumoniae PR, Lelliottia amnigena (Enterobacter amnigenus) PR).

Strains were taken from the collection of microorganisms of the laboratory of prevention of airborne infections of State Institution I. I. Mechnikov Institute of Microbiology and Immunology of National Academy of Medical Sciences of Ukraine, Kharkiv, Ukraine.

Bacterial weighed amounts of test cultures were prepared using the transparency standard of Densi-La-Meter device (PLIVA-Lachema Diagnostika, (Czech Republic)), using McFarland scale.

The impact of filtrates of $L$. rhamnosus GG and $S$. boulardii on growth and reproduction of test strains was studied using the spectrophotometric method according to Buharin (1999). For this purpose, to the experimental weighed amounts of test cultures of pathogen and filtrate of disintegrate or metabolites of probiotic microorganism, we added universal growth medium and then cultivated it. According to changes in the indicators of optical density of final samples compared to the initial, we evaluated the character of the impact of biologically active substances from L. rhamnosus GG and S. boulardii on growth and reproduction of cells of antibiotic-resistant bacteria. The idea of the experiment was determining the inhibiting activity of a new class of metabolites in favourable conditions of growth/reproduction of test cultures of the microorganisms.

The method was applied in polystyrene 96 well microplates manufactured by Eximcargotrade Ltd, Ukraine. Into all experimental samples, we added microbial suspensions of polyresistant gram-negative test cultures and filtrate of disintegrate or metabolite in 1:9 proportion. Considering the results of the high level of anti-microbial activity of the studied substances of lactobacteria and saccharomycetes against pathogenic and conditionally pathogenic microorganisms obtained in previous experiments (Isajenko et al., 2017, 2018), the final concentration of test culture was increased up to $10^{6} \mathrm{CFU} / \mathrm{mL}$, which was 10 times higher than the amount of microorganisms recommended according to the method (MOZ, 2007). In the control samples, we added to the bacteria cultures isotonic solution of sodium chloride $(0.9 \%)$ instead of metabolites; this was positive control - control of growth of the studied test strain.

Wells with negative control contained only isotonic solution of sodium chloride $(0.9 \%)$. After the microplates had been maintained for an hour at temperature $37 \pm 1{ }^{\circ} \mathrm{C}$, we added meat-peptone broth (MPB) with $1 \%$ glucose to all wells and measured optical density of the initial samples using Lisa Scanтм EM analyzer (Erba Mannheim, Czech Republic) at $630 \mathrm{~nm}$ wave length. Then the microplates were incubated at temperature $37 \pm 1^{\circ} \mathrm{C}$ and the values of optical density measured after 5 and 24 hours of cultivation of the studied samples. Measurements of the values of optical density compared to the control indicated an impact of substances from L. rhamnosus GG and S. boulardii on the studied pathogens. Inhibition of growth and reproduction of the studied cultures of bacteria was expressed in the percentage of inhibition of increment (In Inc) of polyresistant gram-negative test strains under the impact of biologically active substances of lactobacteria and saccharomycetes, calculation of which was made using the formula (Buharin, 1999):

In Inc $=($ ODcg - ODedm $) \times 100 \% /$ ODcg, at ODcg $=$ ODc ODac; ODedm $=$ ODe - ODac, where ODc - average of three experiments for the control strain; ODe - average of three experiments for the experimental strain; ODac - average of three experiments for negative control; ODcg - averaged values of three experiments in three replications for optical density of the examined test culture of the microorganism after $5 / 24$ hours of growth in the control (control of growth of studied test culture); ODedm - averaged values of three experiments in three replications for optical density of examined test culture of microorganism after $5 / 24$ hours of growth in the experiment (under the impact of disintegrates and metabolites from L. rhamnosus GG and S. boulardii).
The tests were made three times in three replications. The data were analyzed in Statistica 8.0 (StatSoft Inc., USA). We calculated mean arithmetic (x) and standard deviation of mean arithmetic value (SD). The reliability of the differences between obtained data was determined using the non-parametric U-criterion of Mann-Whitney. Difference between the experimental samples and the control was considered probable at $\mathrm{P}<0.05$.

\section{Results}

The conducted studies revealed that under the impact of the studied probiotic products from L. rhamnosus GG and S. boulardii, growth of $P$. aeruginosa $P R$ test culture was statistically reliably inhibited, which manifested in reduction of optical density (Fig. 1). Extent of inhibition of growth of $P$. aeruginosa PR depended on duration of cultivation. After 5-hour incubation, we observed significant inhibition of growth properties of the pathogen, which did not depend on the examined biologically active substances from $L$. rhamnosus $\mathrm{GG}$ and $S$. boulardii. Maximum inhibition of the microorganism was observed under the impact of metabolites from lactobacteria, obtained at cultivation of primary producers in their disintegrate $(\mathrm{ML})$ - by $95.7 \%(\mathrm{P}<0.05)$. The rest of the studied substances from $L$. rhamnosus $\mathrm{GG}$ and $S$. boulardii affected growth and reproduction of $P$. aeruginosa $\mathrm{PR}$ to a lower extent. At the same time, we found statistically reliable inhibition - within 73.9 $92.5 \%(\mathrm{P}<0.05)$, which indicates a high extent of anti-microbial activity of the filtrates of probiotic strains against this antibiotic-resistant culture of Pseudomonas.

When exposure to the cultivation was prolonged to 24 hours, all examined samples of $L$. rhamnosus $\mathrm{GG}$ and $S$. boulardii had a lethal effect on P. aeruginosa PR: $100 \%$ inhibition of this strain was observed.

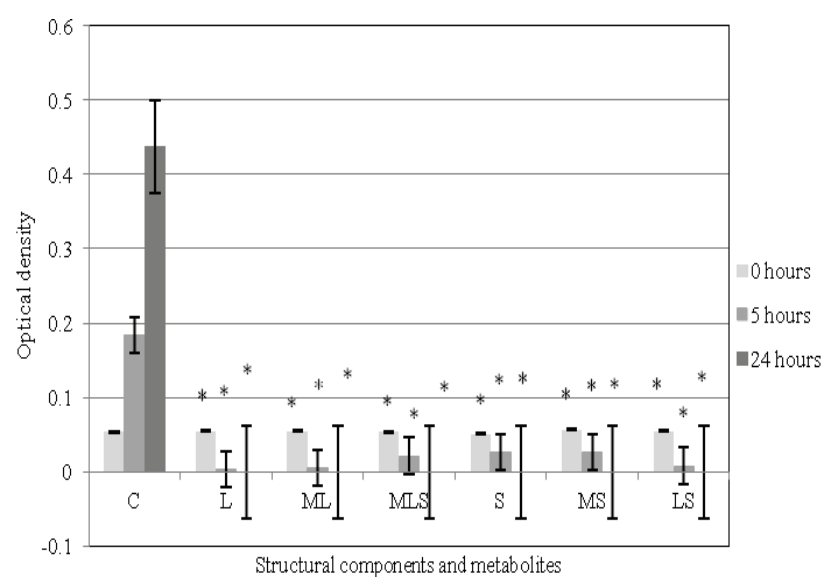

Fig. 1. Anti-microbial activity of filtrates of Lactobacillus rhamnosus GG and Saccharomyces boulardii against polyresistant $P$. aeruginosa $\mathrm{PR}$

strain cultivated in growth media: optical density $\mathrm{x} \pm \mathrm{SD}, \mathrm{n}=9$;

$\mathrm{C}$ - control, $\mathrm{L}$ - filtrates of disintegrates (structural components) of lactobacteria, $\mathrm{ML}$ - metabolites from lactobacteria, MLS - combination of metabolites and saccharomycetes, $\mathrm{S}$ - filtrates of disintegrates (structural components) of saccharomycetes, MS - metabolites from saccharomycetes, obtained through cultivation of saccharomycetes in their disintegrates, LS - metabolites from saccharomycetes, obtained through cultivation of saccharomycetes in disintegrates of lactobacteria;

* - difference of experimental samples compared to control was statistically significant $(\mathrm{P}<0.05)$

Inhibition of growth and reproduction of L. amnigena (E. amnigenus) PR polyresistant strain after five-hour exposure was observed under the impact of all biologically active substances from L. rhamnosus GG and S. boulardii (Fig. 2). According to the obtained results, maximum inhibition of growth of the pathogen was observed in presence of metabolites from L. rhamnosus (ML) (by 93.4\%), which confirms previous results. The presented data indicate that among the examined filtrates of lactobacteria and saccharomycetes, the most notable effect of inhibition of antibiotic-resistant gram-negative test cultures in the logarithmic growth phase was demonstrated by metabolites from 
lactobacteria. Study of impact of biologically active substances of $L$. rhamnosus GG and S. boulardii on growth of $L$. amnigena PR after 24hour incubation demonstrated $100 \%$ inhibition of growth of the examined test culture (Fig. 2).

In stable conditions of cultivation, in which the microbial cells of the two studied microorganisms (P. aeruginosa PR or L. amnigena PR) were kept, we observed partial inhibition of bacteria after 5 hours, and complete inhibition after 24 hours. At the same time, the extent of inhibition of reproduction of the studied pathogens directly proportionally depended on the duration of incubation of the pathogen with the examined probiotic substances. We determined a direct correlational dependence between inhibition of growth and duration of exposure of the influence for disintegrates of lactobacteria $(+0.789)$, metabolites from lactobacteria $(+0.955)$, combination of metabolites from lactobacteria and saccharomycetes $(+0.789)$, disintegrates of saccharomycetes $(+0.926)$, metabolites from saccharomycetes, obtained through cultivation of fungi in disintegrates of lactobacteria $(+0.991)$. The obtained data allow us to draw preliminary conclusions: filtrates of disintegrates and metabolites from probiotic microorganisms have ability to inhibit growth of polyresistant test strains. At the same time the number of microbial cells of bacteria on which the examined substances took effect was higher than the one recommended in methodological documents (Nakaz MOZ Ukrainy 167,2007$)$. The obtained results indicate the high extent of antimicrobial activity of the experimental samples, which in favourable conditions of cultivation of test cultures cause death to bacteria resistant to many antibacterial preparations, which allows us to consider the studied substances promising preparations for alternative therapy of infectious pathologies of different genesis.

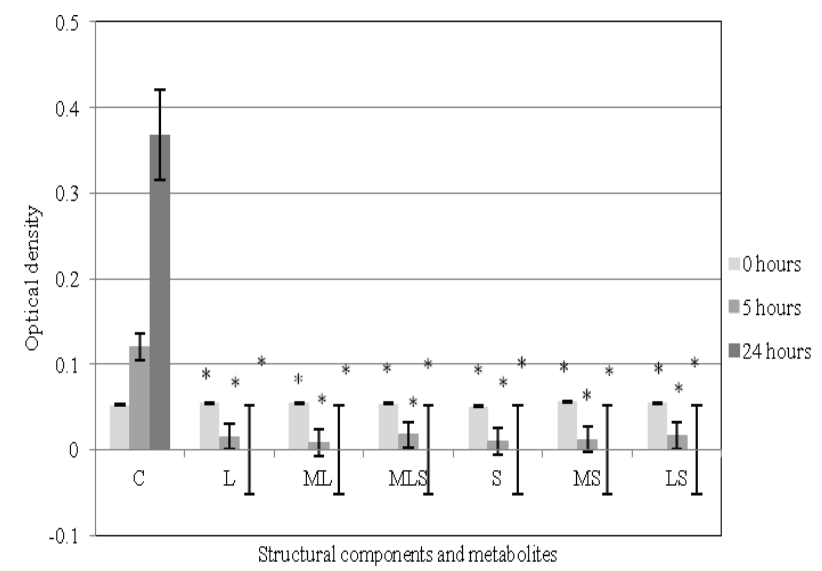

Fig. 2. Anti-microbial activity of filtrates of Lactobacillus rhamnosus GG and Saccharomyces boulardii against $L$. amnigena PR cultivated in growth media, optical density $(x \pm S D, n=9)$ : see Fig. 1

Filtrates of probiotic strains demonstrated anti-microbial activity also against culture of $K$. pneumoniae PR polyresistant strain. At the same time $K$. pneumoniae PR was observed to be more sensitive to samples of probiotic lactobacteria than to substances of saccharomycetes (Fig. 3). Impact of disintegrate and metabolites of L. rhamnosus GG on K. pneumoniae PR contributed to manifested inhibition of growth of the microorganism. In all studied samples of $L$. rhamnosus GG, after five-hour incubation, we observed significant inhibition of growth and reproduction of this test culture; indicators were within the range of $92.7-96.7 \%$. After 24-hour exposure, unfavourable impact on K. pneumoniae PR was caused by all samples of lactobacteria and combination of metabolites of fungi and bacteria, which manifested in $100 \%$ death of the studied conditionally pathogenic microorganism.

Polyresistant strain $K$. pneumoniae PR demonstrated lower sensitivity to $S$. boulardii compared to $P$. aeruginosa PR and L. amnigena PR (Fig. 3). Five-hour exposure of $K$. pneumoniae PR in filtrates of saccharomycetes slowed the growth of the microorganism by $45.1-$ $76.8 \%$. Change in the duration of incubation from 5 hours to 24 hours was accompanied by intensification of inhibition of growth of the pathogen. Filtrates of cultures of saccharomycetes (disintegrate (S) and metabolites, obtained through cultivation of fungi in lactobacteria (LS)) took inhibitory effect also after 24 hours of cultivation (52.7-61.6\%). Products of vital activity of $S$. boulardii (MS) after 24 hours of incubation lethally affected this strain. Taking into account the results, we can draw a conclusion that the intensity of the influence of filtrates of lactobacteria and saccharomycetes on growth and reproduction of test culture depends on individual sensitivity of the species/strain of microorganism.

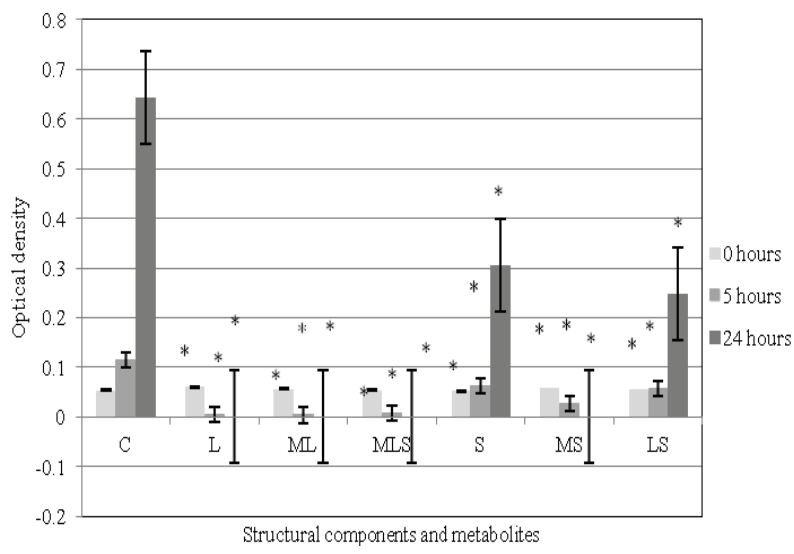

Fig. 3. Anti-microbial activity of filtrates of Lactobacillus rhamnosus GG and Saccharomyces boulardii against K. pneumoniae PR cultivated in growth media, optical density $(x \pm S D, n=9)$ : see Fig. 1

Against the background of decrease in activity of active antibacterial preparations, and also, taking into account the obtained results of significant reduction of reproduction of the studied polyresistant cultures of bacteria up to complete inhibition of their growth, the biologically active substances L. rhamnosus GG and Saccharomyces can be considered promising agents for creating anti-microbial preparations of a new generation.

\section{Discussion}

This study is a fragment of a wider research project devoted to investigating activity of metabolites from $L$. rhamnosus and $S$. boulardii probiotic strains, which are promising for developing new therapeutic and preventive preparations against diseases caused by antibiotic-resistant conditionally pathogenic and pathogenic microorganisms, and could be used universally. For the first time, we have demonstrated results of anti-bacterial effect of filtrates of structural components and cultures of probiotics, grown in disintegrates of probiotic strains, against etiologically significant gram-negative microorganisms, determined using the spectrophotometric method. Earlier, we studied the anti-microbial properties of metabolites from probiotic cultures of lactobacteria against polyresistant conditionally pathogenic gram-positive and gram-negative bacteria, determining the amount of vital microbial cells by inoculation and count of colony-forming units (CFU) in growth media after preincubation of test-cultures with the studied substances. Antibacterial activity of metabolites from saccharomycetes, obtained according to author's method, has not been studied before. In previous experiments, manifested anti-microbial properties of products of vital activity of lactobacteria and combination of metabolites had been proven. According to the literature data, the methods we used (spectrophotometric and count of vital microorganisms), despite partial similarity of studies, give different results. Confirmation of the high level of anti-microbial activity of the samples of lactobacteria studied using different methods, and also demonstration of antibacterial properties of filtrates of saccharomycetes, allow us to state with certainty that the suggested method of obtaining biologically active substances of probiotic origin, without use of traditional growth media, has revealed a promising orientation in developing preparations of metabolite type of new generation with possibility of alternative or additional therapy of diseases caused by pathogens with resistance to a broad range of medications.

The demonstrated data corroborate the anti-microbial effect of disintegrates and metabolites, obtained through cultivation of saccharomycetes in ultrasound disintegrates of probiotic cultures, and correlate well 
with the results of studies by other authors (Bai et al., 2016; Stier \& Bischoff, 2016). Our use of ultrasound waves for disintegrate of $S$. boulardii partly coincides with the report by Ali et al. (2012). The scientists used ultrasound effect on cells of $S$. boulardii, which were in cold distilled water, and then centrifuged them ( 5 minutes, $5500 \mathrm{rpm})$. The obtained supernatant of $S$. boulardii, as in our case, had anti-microbial activity, which was determined in relation to Escherichia coli and Candida albicans.

Other authors proved that metabolites from $S$. boulardii had a bacteriostatic effect on cells of $S$. aureus in amount of $0.1 \mathrm{~mL}$ and showed no activity against $E$. coli (Stefania et al., 2017). Individual sensitivity of test cultures to substances of saccharomycetes, observed by Stefania et al. (2017), has been confirmed by our results. The polyresistant strain $K$. pneumoniae PR demonstrated higher sensitivity to biologically active substances of $L$. rhamnosus GG compared to disintegrates and metabolites from S. boulardii.

By adding silver nitrate $\left(\mathrm{AgNO}_{3}\right)$ to supernatant of $S$. boulardii, Sahib et al. (2017) obtained a biologically active substance that demonstrated anti-bacterial properties against a number of polyresistant microorganisms: S. aureus, S. pyogenes, E. coli, K. pneumoniae, E. aerogens, S. typhi, A. baumannii, $P$. auroginosa and $P$. mirabilis. Anti-microbial effect of the products of vital activity of saccharomycetes against antibiotic-resistant bacteria corresponded to the results of our experiments. At the same time, metabolites obtained according to the author's method, without using growth media, had antibacterial properties from the start and therefore this needs no additional elaboration.

The demonstrated data on the high level of anti-microbial activity of filtrates of disintegrates of saccharomycetes and filtrates of cultures of saccharomycetes, obtained through cultivation of primary producers in disintegrates, and also with cultivation of fungi in disintegrates of lactobacteria, indicate prospects of constructing anti-microbial preparations of a new generation.

Anti-microbial effect of derivatives and products of vital activity of L. rhamnosus GG against a broad range of microorganisms was determined by a number of authors (Mančušková et al., 2017; Oliveira et al., 2017). Hagen Frickmann (2018) confirmed impact of supernatant of L. rhamnosus GG on vital activity of Staphylococcus aureus and S. epidermidis. Daba \& Saidi (2015) determined antibacterial properties of metabolites of probiotic strains against $P$. aeruginosa and Escherichia coli. Liévin-Le \& Servin (2014) demonstrated absence of anti-microbial effect of probiotic strains of Lactobacillus against pathogenic microorganisms along with bactericidal effect of their supernatants. After 4 hours of exposure to products of L. rhamnosus GG, vital activity of Shigella was observed to be reduced by $\sim 4 \log \mathrm{CFU} / \mathrm{mL}$, Listeria and enteropathogenic E. coli from 3 to $4 \log \mathrm{CFU} / \mathrm{mL}$, and the number of Salmonella typhimurium decreased by $\sim 5 \log$ CFU/mL (Liévin-Le \& Servin, 2014). The filtrates we demonstrated showed more notable anti-microbial effect and after 5 hours of influence inhibited growth of bacteria polyresistant to anti-bacterial preparations by $85.6-96.7 \%$. Twenty-four hour incubation of microorganisms in the studied samples of lactobacteria was accompanied by $100 \%$ inhibition of test cultures.

The data we obtained well correlate with the results of studies by Sambanthamoorthy (2014), who studied anti-microbial properties of metabolites from $L$. rhamnosus and $L$. jensenii against microorganisms resistant to a broad range of medications: A. baumannii, E. coli and $S$. aureus. Efficiency of products of vital activity of $L$. rhamnosus equaled $96-97 \%$ against $A$. baumannii and $72-85 \%$ against $E$. coli. For two examined strains of $S$. aureus, the activity was observed within $80 \%$ and $93 \%$. Similar results were obtained for K. pneumoniae. In our experiments, the high level of anti-microbial activity of metabolites from lactobacteria was confirmed; it manifested in inhibition of growth of $P$. aeruginosa PR by $88.3-95.7 \%$, L amnigena PR by $85.6-93.4 \%$, $K$. pneumoniae PR by $92.7-96.7 \%$ after 5 hours of incubation and complete death of all pathogens after 24 hours.

The individual sensitivity of polyresistant strains of microorganisms to substances of lactobacteria and saccharomycetes demonstrated in this paper, is corroborated by the results obtained by other authors. Thus, exopolysaccharides obtained from $10^{8} \mathrm{CFU} / \mathrm{mL}$ of L. rhamnosus GG inhibited growth of $C$. albicans over 24 hours. Lower initial concentra- tion of lactobacteria $\left(10^{7} \mathrm{CFU}\right)$ was observed to be insufficient for producing metabolites with anti-fungicidal activity (Allonsius et al., 2017). It should be mentioned that initial concentration of cells of probiotic strains, from which the authors obtained metabolites with high antifungicidal properties, corresponded to the amount of the primary producer used in our experiment.

In the next study the scientists examined supernatant and concentrated metabolites from L. rhamnosus 231 culture grown over 18 hours in MRS medium, which manifested notable anti-microbial properties against $P$. aeruginosa, E. coli, E. aerogenes, $S$. aureus, Salmonella spp., Helicobacter pylori, Campylobacter jejuni, Bacillus cereus, B. megaterium and Listeria monocytogenes. Concentration of the primary producer equaled $10^{8}$ microbial cells per $1 \mathrm{~mL}$, which also corresponded to the results of our experiments (Ambalam et al., 2009).

The presented data about the impact of the derivatives of $L$. rhamnosus probiotic strain on pseudomonads also correlate with the results of a study by Al-Malkey et al. (2017). The authors determined: metabolites obtained from $L$. rhamnosus through cultivation in MRS broth over 24 hours at $37^{\circ} \mathrm{C} 5-10 \% \mathrm{CO}_{2}$ manifested anti-microbial effect against $P$. aeruginosa resistant to a broad range of drugs. At the same time, metabolites from L. acidophilus, obtained in a similar way, had no antimicrobial properties against the examined polyresistant pathogen. The described results confirm the data of Brzozowski et al. (2011), according to whom $L$. rhamnosus CCM 1825 strain produced a higher number of anti-microbial protein substances with polysaccharides and phosphates than L. fermenti 126 culture. Unlike the above mentioned studies, the method we used for obtaining metabolites from $L$. rhamnosus $\mathrm{GG}$ and $S$. boulardii and their combination without using traditional growth media, allows one to obtain biologically active substances with notable anti-microbial effect from different strains of bacteria and fungi (Isajenko et al., 2017; Isajenko et al., 2018).

Comparing extent of anti-microbial activity of the studied ultrasound disintegrates and metabolites from $S$. boulardii and L. rhamnosus GG with similar studies performed by other scientists suggests high antibacterial properties of products of vital activity of lactobacteria and saccharomycetes with a possibility of promising development of preventive and therapeutic preparations of a new generation.

\section{Conclusions}

We characterized a high level of anti-microbial activity of products of vital activity and structural components of probiotic strains of lactobacteria and saccharomycetes using the spectrophotometric method, the extent of the impact of which depended on duration of incubation. The manifested antimicrobial effect of biologically active substances from L. rhamnosus GG and S. boulardii against antibiotic-resistant microorganisms in logarithmic growth phase, in presence of nutrients, was observed to be reduction by $45.1-95.0 \%$. Twenty four hour exposure of polyresistant strains in L. rhamnosus GG samples was accompanied by $100 \%$ death of the test cultures, and with filtrates of $S$. boulardii - reduction by $52.7-100.0 \%$. Among all of the examined substances, maximum inhibiting effect against all studied polyresistant representatives was observed under the impact of metabolites from $L$. rhamnosus GG. The suggested method of obtaining biologically active substances of probiotic origin, without using traditional growth media, has revealed a promising orientation for developing metabolite type preparations of a new generation with a possibility of alternative or additional therapy for diseases caused by pathogens resistant to broad range of medications. The metabolite complexes of $L$. rhamnosus GG and $S$. boulardii, demonstrated by the authors, despite the necessity for further comprehensive study, can be considered promising substances for creating antimicrobial preparations of a new generation.

\section{References}

Ali, M. A. E., Janson, J.-C., \& Ali, E. (2012). Antimicrobial potential of Saccharomyces boulardii extracts and fractions. Journal of Applied Sciences Research, 8(8), 4537-4543.

Allonsius, C. N., van den Broek, M. F. L., De Boeck, I., Kiekens, S., Oerlemans, E. F. M., Kenn, F., Vandenheuvel, D., Cos, P., Delputte, P., \& Lebeer, S. (2017). 
Interplay between Lactobacillus rhamnosus GG and Candida and the involvement of exopolysaccharides. Microbial Biotechnology, 10(6), 1753-1763.

Al-Malkey, M. K., Munira, C. I., Abo Al-Hur, F. J., Mohammed, S. W., \& Nayyefa, H. J. (2017). Antimicrobial effect of probiotic Lactobacillus spp. on Pseudomonas aeruginosa. Journal of Contemporary Medical Sciences, 3(10), 218-223.

Alokomi, H. L., Skytta, E., Saarela, M., Mattila-Sandholm, T., Latva-Kala, K., \& Helander, I. M. (2000). Lactic acid permeabilizes gram-negative bacteria by disrupting the outer membrane. Applied and Environmental Microbiology, 66, 2001-2005.

Ambalam, P. S., Prajapati, J. B., Dave, J. M., Baboo, M. N., Ljungh, Å., \& Vyas, B. R. M. (2009). Isolation and characterization of antimicrobial proteins produced by a potential probiotic strain of human Lactobacillus rhamnosus 231 and its effect on selected human pathogens and food spoilage organisms. Microbial Ecology in Health and Disease, 21, 211-220.

Arcilla, M. S., Hattem, J. M., Haverkate, M. R., Bootsma, M. C. J., van Genderen, P. J. J., Goorhuis, A., Grobusch, M. P., Lashof, A. M. O., Molhoek, N. Schultsz, C., Stobberingh, E. E., Verbrugh, H. A., Jong, M. D., Melles, D. C., \& Penders, J. (2017). Import and spread of extended-spectrum $\beta$-lactamaseproducing Enterobacteriaceae by international travellers (COMBAT study): A prospective, multicentre cohort study. Lancet Infectious Diseases, 17(1), 78-85.

Badaoui Najjar, M., Kashtanov, D., \& Chikindas, M. L. (2009). Natural Antimicrobials \&-poly-L-lysine and nisin A for control of oral microflora. Probiotics and Antimicrobial Proteins, 1(2), 143.

Bai, A., Weaver, M., Bao, F., Chan, E. D., \& Bai, X. (2016). Saccharomyces boulardii produces a factor that inhibits Mycobacterium intracellular burden in human macrophages. Advances in Microbiology, 6(13), 965-974.

Bechinger, B., \& Gorr, S. U. (2016). Antimicrobial peptides: Mechanisms of action and resistance. Journal of Dental Research, 96, 3.

Beyer, G., Hiemer-Bau, M., Ziege, S., Edlund, C., Lode, H., \& Nord, C. E. (2000). Impact of moxifloxacin versus claritromycin on normal oropharyngeal microflora. European Journal of Clinical Microbiology and Infectious Diseases, 19(7), 548-550

Brzozowski, B., Bednarski, W., \& Gołek, P. (2011). The adhesive capability of two Lactobacillus strains and physicochemical properties of their synthesized biosurfactants. Food Technology and Biotechnology, 49, 177-186.

Buharin, O. V. (1999). Persistencija patogennyh bakterij [Persistence of pathogennic bacteria]. Medicina, Moscow (in Russian).

Daba, H., \& Saidi, S. (2015). Detection of bacteriocin-producing lactic acid bacteria from milk in various farms in north-east Algeria by a new procedure. Agronomy Research, 13(4), 907-918.

Dorofeev, J. J., Koljado, E. V., Koljado, V. B., \& Beskrovnaja, E. V. (2017). Dinamika smertnosti ot infekcionnyh i parazitarnyh zabolevanij v Altajskom krae [Dynamics of mortality from infectious and parasitic diseases in the Altai Territory]. Medicina v Kuzbasse, 16(4), 91-95 (in Russian).

Ebbensgaard, A., Mordhorst, H., Aarestrup, F. M., \& Hansen, E. B. (2018). The role of outer membrane proteins and lipopolysaccharides for the sensitivity of Escherichia coli to antimicrobial peptides. Frontiers in Microbiology, 9, 2153.

El-Halfawy, O. M., \& Valvano, M. A. (2013). Chemical communication of antibiotic resistance by a highly resistant subpopulation of bacterial cells. PLoS One, 8(7), e68874.

Forestier, C., Champs, C. D., Vatoux, C., \& Joly, B. (2001). Probiotic activities of Lactobacillus casei rhamnosus: In vitro adherence to intestinal cells and antimicrobial properties. Research in Microbiology, 152, 167-173.

Frickmann, H. (2018). Influence of probiotic culture supernatants on in vitro biofilm formation of staphylococci. European Journal of Microbiology and Immunology, 2018, 38.

Gupta, R., \& Srivastava, S. (2014). Antifungal effect of antimicrobial peptides (AMPs LR14) derived from Lactobacillus plantarum strain LR/14 and their applications in prevention of grain spoilage. Food Microbiology, 42, 1-7.

Isayenko, O. Y., Knysh, O. V., Babych, Y. M., Ryzhkova, T. N., \& Dyukareva, G. I. (2019). Effect of disintegrates and metabolites of Lactobacillus rhamnosus and Saccharomyces boulardii on biofilms of antibiotic resistant conditionally pathogenic and pathogenic bacteria. Regulatory Mechanisms in Biosystems, 10(1), 3-8.

Jakovlev, S. A. (2017). Infekcionnye zabolevanija kak global'naja problema sovremennosti [Infectious diseases as a global problem of our time]. Territorija Nauki, 1, 20-25 (in Russian).

Kaktcham, P. M., Zambou, N. F., Fonteh, A. F., Sieladie, D. V., \& Tchouanguep, M. F. (2011). Characterization of bacteriocin produced by Lactobacillus rhamnosus $1 \mathrm{~K}$ isolated from traditionally fermented milk in the western highlands region of Cameroon. New York Science Journal, 4(8), 121-128.

Kraker, M. E. A., Stewardson, A. J., \& Harbarth, S. (2016). Will 10 million people die a year due to antimicrobial resistance by 2050? PLoS Medicine, 13(11), e1002184
Liévin-Le, M. V., \& Servin, A. L. (2014). Anti-infective activities of Lactobacillus strains in the human intestinal microbiota: From probiotics to gastrointestinal anti-infectious biotherapeutic agents. Clinical Microbiology Reviews, 27(2), 167-199.

Lupo, A., Haenni, M., \& Madec, J. Y. (2018). Antimicrobial resistance in Acinetobacter spp. and Pseudomonas spp. Microbiology Spectrum, 2018, 6, 3 .

Malanovic, N., \& Lohner, K. (2016). Gram-positive bacterial cell envelopes: The impact on the activity of antimicrobial peptides. Biochimica et Biophysica Acta, 1858(5), 936-946.

Mančušková, T., Medved’ová, A., \& Valík, L. (2017). Antimicrobial potential of probiotics in combination with start er lactic acid bacteria. Scientia Agriculturae Bohemica, 48(4), 208-215.

Mirnejad, R., Vahdati, A. R., Rashidiani, J., Erfani, M., \& Piranfar, V. (2013). The antimicrobial effect of Lactobacillus casei culture supernatant against multiple drug resistant clinical isolates of Shigella sonnei and Shigella flexneri in vitro. Iranian Red Crescent Medical Journal, 15(2), 122-126.

Mitsakakis, K., Kaman, W. E., Elshout, G., Specht, M., \& Hays, J. P. (2018). Challenges in identifying antibiotic resistance targets for point-of-care diagnostics in general practice. Future Microbiology. 13(10), 1157-1164.

Nes, I. F., \& Holo, H. (2000). Class II antimicrobial peptides from lactic acid bacteria. Biopolymers, 55(1), 50-61.

Nikaido, H. (2011). Structure and mechanism of RND-type multidrug efflux pumps. Enzymology and Related Areas of Molecular Biology, 77, 1-60.

Nomoto, K. (2005). Prevention of infections by probiotics. Journal of Bioscience and Bioengineering, 100(6), 583-592.

Oliveira, L. C., Silveira, A. M. M., Monteiro, A. S., Dos Santos, V. L., Nicoli, J. R, Azevedo, V. A. C., Soares, S. C., Dias-Souza, M. V., \& Nardi R. M. D. (2017) In silico prediction, in vitro antibacterial spectrum, and physicochemical properties of a putative bacteriocin produced by Lactobacillus rhamnosus Strain L156.4. Frontiers in Microbiology, 8, 876.

Östholm, B. Å., Tärnberg, M., Nilsson, M., Nilsson, L. E., Hanberger, H., Hällgren, A., \& Southeast Sweden Travel Study Group (2018). Duration of travel-associated faecal colonisation with ESBL-producing Enterobacteriaceae - A one year follow-up study. PLoS One, 13(10), e0205504.

Ponomarev, S. I., \& Jakovlev, S. A. (2017). Infekcionnye zabolevanija kak medikosocialnaja problema [Infectious diseases as a medical and social problem] Sinergija, 1, 110-119 (in Russian).

Portella, A. C. F., Karp, S., Scheidt, G. N., Woiciechwski, A. L., Parada, J. L., \& Soccol, C. R. (2009). Modelling antagonic effect of lactic acid bacteria supernatants on some pathogenic bacteria. Brazilian Archives of Biology and Technology, 52, 29-36.

Ramsamy, Y., Essack, S. Y., Sartorius, B., Patel, M., \& Mlisana, K. P. (2018). Antibiotic resistance trends of ESKAPE pathogens in Kwazulu-Natal, South Africa: A five-year retrospective analysis. African Journal of Laboratory Medicine, 7(2), 887

Richter, M. F., \& Hergenrother, P. J. (2019). The challenge of converting Grampositive-only compounds into broad-spectrum antibiotics. Annals of the New York Academy of Sciences, 1435(1), 18-38

Sahib, F. H., Aldujaili, N. H., \& Alrufae, M. M. (2017). Biosynthesis of silver nanoparticles using Saccharomyces boulardii and study their biological activities. European Journal of Pharmaceutical and Medical Research, 4(9), 65-74.

Sambanthamoorthy, K., Feng, X., Patel, R., Patel, S., \& Paranavitana, C. (2014). Antimicrobial and antibiofilm potential of biosurfactants isolated from lactobacilli against multi-drug-resistant pathogens. BMC Microbiology, 14, 197.

Santajit, S., \& Indrawattana, N. (2016). Mechanisms of antimicrobial resistance in ESKAPE pathogens. Biomed Research International, 2016, 2475067.

Sarika, A. R., Lipton, A. P., \& Aishwarya, M. S. (2010). Bacteriocin production by a new isolate of Lactobacillus rhamnosus GP1 under different culture conditions. Food Science and Technology, 2(5), 291-297.

Stefania, D. M., Miranda, P., Diana, M., Claudia, Z., \& Rita, P. (2017). Antibiofilm and antiadhesive activities of different synbiotics. Journal of Probiotics and Health, 5, 182.

Stier, H., \& Bischoff, S. (2016). Influence of Saccharomyces boulardii CNCM I-745 on the gut-associated immune system. Clinical and Experimental Gastroenterology, 9, 269-279.

Tsutsui, A., \& Suzuki, S. (2018). Japan nosocomial infections surveillance (JANIS) A model of sustainable national antimicrobial resistance surveillance based on hospital diagnostic microbiology laboratories. BMC Health Services Research, 18,799

Ursova, N. I. (2013). Aktualnye problemy i nereshennye problemy probiotikoterapii [Relevant problems and unsolved problems of probiotic therapy]. Lechashhij Vrach, 8, 60-65 (in Russian).

Wald, E. R. (2011). Acute otitis media and acute bacterial sinusitis. Clinical Infectious Diseases, 52(4), 277-283.

Wang, Z., Shen, Y., \& Haapasalo, M. (2017). Antibiofilm peptides against oral biofilms. Journal of Oral Microbiology, 9(1), 1327308 